\title{
Prior short-term consumption of resistant starch enhances postprandial insulin sensitivity in healthy subjects
}

\author{
M. D. Robertson ${ }^{1}$, J. M. Currie 1 , L. M. Morgan ${ }^{3}$, D. P. Jewell ${ }^{2}$, K. N. Frayn ${ }^{1}$ \\ ${ }^{1}$ Oxford Lipid Metabolism Group, OCDEM, Churchill Hospital, Oxford, UK \\ 2 Nuffield Department of Gastroenterology, University of Oxford, UK \\ ${ }^{3}$ School of Biomedical and Life Science, University of Surrey, Guildford, UK
}

\begin{abstract}
Aims/hypothesis. Diets rich in insoluble-fibre are linked to a reduced risk of both diabetes and cardiovascular disease; however, the mechanism of action remains unclear. The aim of this study was to assess whether acute changes in the insoluble-fibre (resistant starch) content of the diet would have effects on postprandial carbohydrate and lipid handling.

Methods. Ten healthy subjects consumed two identical, low-residue diets on separate occasions for $24 \mathrm{~h}$ (33\% fat; $<2$ g dietary fibre). Of the diets one was supplemented with $60 \mathrm{~g}$ resistant starch (Novelose $260)$. On the following morning a fibre-free meal tolerance test (MTT) was carried out (59 g carbohydrate; $21 \mathrm{~g}$ fat; $2.1 \mathrm{~kJ}$ ) and postprandial insulin sensitivity $\left(\mathrm{SI}_{\mathrm{ORAL}}\right)$ assessed using a minimal model approach.

Results. Prior resistant starch consumption led to lower postprandial plasma glucose $(p=0.037)$ and insulin
\end{abstract}

$(p=0.038)$ with a higher insulin sensitivity $(44 \pm 7.5 \mathrm{vs}$ $26 \pm 3.5 \times 10^{-4} \mathrm{dl} \mathrm{kg}^{-1} \mathrm{~min}^{-1}$ per $\left.\mu \mathrm{Uml}^{-1} ; p=0.028\right)$ and C-peptide-to-insulin molar ratio $(18.7 \pm 6.5$ vs $9.7 \pm 0.69 ; p=0.017)$. There was no effect of resistant starch consumption on plasma triacylglycerol although non-esterified fatty acid and 3-hydroxybutyrate levels were suppressed $5 \mathrm{~h}$ after the meal tolerance test.

Conclusion. Prior acute consumption of a high-dose of resistant starch enhanced carbohydrate handling in the postprandial period the following day potentially due to the increased rate of colonic fermentation. [Diabetologia (2003) 46:659-665]

Keywords Resistant starch, dietary fibre, short chain fatty acids, glucagon-like peptide 1, postprandial, insulin sensitivity.
A reduction in insulin sensitivity has been linked to an increased risk of both Type 2 diabetes and cardiovascular disease [1]. Soluble fibre improves insulin sensi-

Received: 2 December 2002 / Revised: 27 January 2003

Published online: 24 April 2003

(C) Springer-Verlag 2003

Corresponding author: Dr. M. D. Robertson, Oxford Lipid Metabolism Group, OCDEM, Churchill Hospital, Oxford, OX3 7LJ UK

E-mail: denise.robertson@oxlip.ox.ac.uk

Abbreviations: RS, resistant starch; RDS, rapidly digestible starch; MTT, meal tolerance test; $\mathrm{SI}_{\mathrm{ORAL}}$, insulin sensitivity; TG, triacylglycerol; 3-OHB, 3-hydroxybutyrate; GLP-1, glucagon-like peptide 1; GE, glucose effectiveness; VLDL, very low density lipoprotein; GI, glycaemic index. tivity by increasing the viscosity of the stomach and small intestinal contents [2] and so impeding carbohydrate digestion and absorption [3]. Over time, the lower circulating insulin [4] levels lead to the up-regulation of both insulin receptors [5] and secondary signalling molecules resulting in increased tissue insulin sensitivity. The addition of a non-viscous, insoluble fibre to a meal has no acute effect on either postprandial glucose or insulin responses. Yet, in population studies it is insoluble-fibre and not viscous-fibre that has been shown to relate to protection from both cardiovascular disease and diabetes $[6,7,8]$.

The mechanism of action of this insoluble, non-viscous fibre remains obscure. The increased insulin sensitivity associated with cereal fibre is often in context of "whole grain" consumption [9, 10]. However, in 
addition to fibre, unrefined grains contain biologically active components such as antioxidants, minerals and phytoestrogens [11] and so the benefits of fibre per se are less well-defined.

Resistant starch (RS) acts as an insoluble fibre and by definition is resistant to enzymatic digestion in the small intestine and is non-viscous. Like other insoluble fibres it is fermented in the colon by the microflora which release carbon dioxide, methane, hydrogen and metabolically active short chain fatty acids (primarily acetate, propionate and butyrate) which are utilized by the colonic epithelium and enter the portal circulation. In isolation, SCFA have been shown to have effects on adipose tissue lipolysis [12, 13], hepatic gluconeogenesis [14] and insulin secretion [15] although the physiological significance of these observations for insulin sensitivity following dietary fibre remains to be established.

In Europe, the daily intake of RS is low (3-5 g) [16]. However, with the recent development of highRS flours which are process tolerant and improve food

Table 1 Baseline characteristics of subject group

\begin{tabular}{lcc}
\hline & Mean & Range \\
\hline Age (yrs) & 47.2 & $23-65$ \\
BMI (Kg/m $\left.{ }^{2}\right)$ & 26.9 & $20.3-35.9$ \\
Body weight $(\mathrm{kg})_{\text {Fat mass }^{\mathrm{a}}(\%)}^{78.3}$ & $51.9-107.4$ \\
Lean mass $^{\mathrm{a}}(\%)$ & 34.2 & $16.3-53.7$ \\
Plasma TG (mmol/l) & 65.7 & $46.2-83.6$ \\
Plasma Glucose (mmol/l) & 1.2 & $0.7-2.0$ \\
Plasma Insulin (mU/l) & 5.2 & $4.5-6.1$ \\
HOMA-IR $^{\mathrm{b}}$ & 4.5 & $0.6-7.6$ \\
\end{tabular}

a Calculated by electrical impedence (Bodystat 1500, Bodystat, Isle of Man, UK)

${ }^{\mathrm{b}}$ Homeostatic Model Assessment texture there is the potential within the food industry to develop "fibre-fortified" processed food products which could increase the daily intake of RS. Although the effects of RS intake on colon health are now well established [17], less is known about the potential impact this might have on glycaemic control and postprandial metabolism.

This aim of this study was to investigate the metabolic effects of a high intake of RS (60 g) taken over a 24-h period, when other nutrients have been controlled. Indices of insulin sensitivity were measured the following day when colonic fermentation of the undigested carbohydrate was predicted to be active.

\section{Subjects and Methods}

Subjects. Ten healthy subjects (six female) participated in this study. Pre-study fasting values for the subjects group are presented in Table 1. All subjects were healthy and none were currently taking any medication. All subjects gave written informed consent and the study was approved by the Oxfordshire Clinical Research Ethics Committee.

Study Design. The study was conducted in a single-blind crossover design. In order to standardize nutritional status, subjects consumed either a high-resistant starch diet for $24 \mathrm{~h}$ or a low resistant starch for $24 \mathrm{~h}$ before the study day. The basal diet was provided in a ready-to-eat form with $33 \%$ energy from fat, $24 \%$ from protein and $42 \%$ from carbohydrate with less than $2 \mathrm{~g}$ dietary fibre (Table 2). The high-resistant starch diet consisted of the basal diet supplemented with $100 \mathrm{~g}$ of high-amylose maize starch (60 g RS, 40 g RDS; Novelose 260, National Starch and Chemical, Manchester UK). The RS was split into four $25 \mathrm{~g}$ doses and mixed with jelly (Nestlé, Switzerland) to provide four portions of RS-jelly eaten at specified time-points during the day. The low-resistant starch diet consisted of the basal diet supplemented with $40 \mathrm{~g}$ waxy-maize starch (40 g RDS; Amioca, National Starch and Chemical) to match the digestible

Table 2 Example of 24-h diet provided to a male subject weighing $70 \mathrm{~kg}$

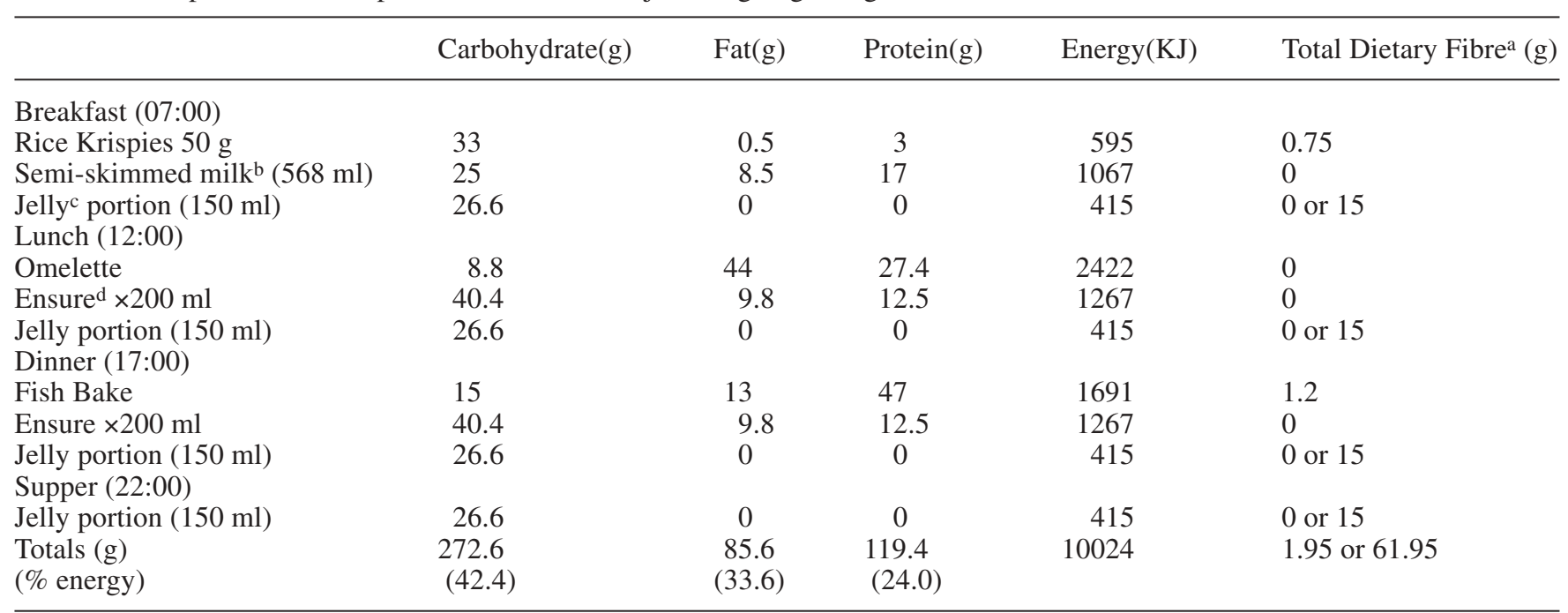

a Calculated by the AOAC method 991.43

b 1 pint of milk was provided for use in cereal and in tea/coffee. c $600 \mathrm{ml}$ of jelly made up to contain either $100 \mathrm{~g}$ Novelose 260 or $40 \mathrm{~g}$ Amioca, split into four equal portions.

d Ensure Plus (Abbott Laboratories, Kent, UK) 
starch component of the Novelose 260. The dietary starch was split into four $10 \mathrm{~g}$ doses and mixed with jelly as above.

The energy content of the diet was estimated according to each subject's individual energy requirements, based on age, weight, height and sex [18]. A multiplication factor of 1.5 was used to correct for normal daily activity. Subjects were asked not to smoke or exercise during the dietary period.

The following morning an antecubital cannula was inserted under local anaesthetic (1\% lignocaine). A standard fibre-free meal tolerance test (MTT) was administered as a $2.1 \mathrm{~kJ}$ chocolate drink (59 g carbohydrate, $21 \mathrm{~g}$ fat and $19 \mathrm{~g}$ protein) at time $=0$. Blood samples were taken every $10 \mathrm{~min}$ for $2 \mathrm{~h}$ after the meal and then every $30 \mathrm{~min}$ for the remaining $3 \mathrm{~h}$.

Blood analysis. Whole blood for metabolite and insulin determination was collected into heparinized syringes (Sarstedt, Leicester, UK). Plasma glucose, triacylglycerol (TG) (Instrumentation Laboratory, Warrington, UK) and NEFA concentrations (Alpha Laboratories, Eastleigh, UK) were measured enzymatically using an IL Monarch automated analyzer. Plasma for 3-hydroxybutyrate (3-OHB) and lactate determination were deproteinized with $7 \%$ (wt/vol) perchloric acid and concentrations measured enzymatically. Metabolites were batch analyzed and showed an intra-assay variation of less than 2.5\%. Insulin (Pharmacia \& Upjohn, Milton Keynes, UK) and C-peptide levels (Linco, Miss., USA) were measured by radioimmunassay using commercially available kits. Blood for GLP-1 analysis was collected into potassium-EDTA containing $200 \mathrm{KIU}$ aprotinin/ml (Bayer, Newbury, UK). GLP-1 was assayed on unextracted plasma by a double-antibody disequilibrium method [19]. The antiserum was specific for the C-terminal amidated form of GLP-1 cross-reacting 100\% with GLP(7-36 amide). The detection limit was $5 \mathrm{pmol} / \mathrm{l}$. Lipoprotein fractions $S_{f}>400$ and $S_{f} 20-400$ were prepared by density gradient ultracentrifugation [20]. Ultracentrifugation was carried out at $202,000 \mathrm{~g}$ in a SW $40 \mathrm{Ti}$ swinging bucket rotor (Beckman, High Wycombe, Bucks., UK) at $15^{\circ}$. TG concentrations in the lipoprotein fractions were measured enzymatically using an IL automated analyzer (IL, Warrington, UK). Short chain fatty acids were analyzed by gas-liquid chromatography. Heparinized plasma was de-proteinized with $16 \%$ metaphosphoric acid and denatured for $30 \mathrm{~min}$ at $60^{\circ} \mathrm{C}$ before splitless injection of $1 \mu \mathrm{l}$ of the supernatant onto a FFAP column (Agilent Technologies) [21]. Isovaleric acid was used as the internal standard. All samples with the exception of plasma lipoproteins were frozen at $-20^{\circ} \mathrm{C}$ until batch analysis.

Insulin sensitivity. Insulin sensitivity $\left(\mathrm{SI}_{\mathrm{ORAL}}\right)$ was assessed in the postprandial state using a recently described minimal model index [22]. The model provides an estimate of $\mathrm{SI}_{\mathrm{ORAL}}$ following carbohydrate ingestion in each individual and following each meal. The insulin sensitivity calculated by this method utilizes cumulative integrated AUC measures of both insulin and glucose concentration assuming that the total glucose disposal from the system after 120 min (or when basal values have been reached) equals the glucose entering the peripheral circulation allowing for first pass extraction by the liver. Insulin-independent mechanisms also contribute to total glucose disposal and a constant rate of glucose effectiveness (GE) has been assumed for the whole time interval.

$\mathrm{S}_{\mathrm{I}(\text { oral })}=\mathrm{fxD}_{\text {oral }} \frac{\frac{\mathrm{AUC}[\Delta \mathrm{g}(\mathrm{t}) / \mathrm{g}(\mathrm{t})]}{\mathrm{AUC}[\Delta \mathrm{g}(\mathrm{t})]}-\mathrm{GE} \times \operatorname{AUC}[\Delta \mathrm{g}(\mathrm{t}) / \mathrm{g}(\mathrm{t})]}{\mathrm{AUC}[\Delta \mathrm{i}(\mathrm{t})]}$

where AUC denotes the area under the curve calculated from time zero until the end of the test, GE=glucose effectiveness, which was fixed at $0.024 \mathrm{dl} / \mathrm{kg} \cdot \min [23], \mathrm{D}_{\text {oral }}$ is the dose of in-

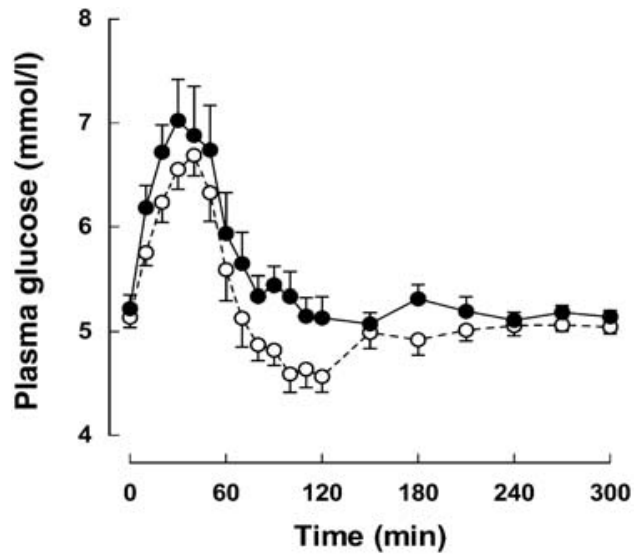

Fig. 1 Mean $( \pm$ SEM) plasma glucose concentration during a meal tolerance test when preceded by either $24 \mathrm{~h}$ on a high-RS (O) or low-RS (O) diet. $n=10$. Repeated measures ANOVA showed a significant effect of preceding diet $(p=0.037)$

gested carbohydrate per unit of body weight $(\mathrm{mg} / \mathrm{kg})$ and $\mathrm{f}$ is the fraction of ingested carbohydrate reaching the peripheral circulation as glucose. The test meals provided in our study contained a high proportion of glucose as the source of carbohydrate and so a nominal value for $\mathrm{f}$ of 0.8 was chosen for all subjects.

The incremental C-peptide to insulin ratio over the first $2 \mathrm{~h}$ of the study, an index of hepatic insulin extraction, was calculated with the trapezoid method.

Breath analysis. Samples of alveolar air were collected in the fasting state and hourly throughout the study using a modified Haldane-Priestley tube (Quintron GaSampler System, Milwaukee, Wis., USA). Duplicate samples of expired breath were analyzed using a GMI Breath Hydrogen analyzer (Renfrew, UK) and the results expressed as ppm $\mathrm{H}_{2}$.

Statistics. Time course data were analyzed by repeated measures ANOVA when normally distributed using SPSS (SPSS, Chicago, USA). AUC were calculated using the trapezoid method and summary measures were analyzed using non-parametric t-tests (Wilcoxon's test). Pearson correlations between variables were done following the high-RS diet only $(n=10)$. A $p$ value of less than 0.05 was considered statistically significant.

\section{Results}

Carbohydrate metabolism. The plasma glucose concentrations following an MTT preceded by both 24-h highand low-RS diets are shown in Fig. 1. The glucose excursion was lower at all time-points following the high$\mathrm{RS}$ diet with a reactive hypoglycaemia at $2 \mathrm{~h}$. The plasma insulin concentrations followed a similar pattern although the peak was reached approximately $10 \mathrm{~min}$ later than with glucose. Postprandial insulin levels were lower following the high-RS diet. Plasma C-peptide concentrations however, did not show this effect (Fig. 2). Plasma GLP-1 during the MTT rose from a mean basal level of $11 \mathrm{pmol} / \mathrm{l}$ to reach a mean peak concentration of $42 \mathrm{pmol} / \mathrm{l}$ after $1 \mathrm{~h}$. There was no effect of preceding diet on the plasma GLP-1 excursion (data not shown). Table 3 shows the markers of insulin sensitivity calculated from both fasting and postprandi- 
al data. There was no difference between the two diets in either basal insulin resistance or percent of beta-cell function when assessed using the HOMA model. However, postprandial insulin sensitivity assessed using the minimal model approach was increased following the high-RS diet compared to the low-RS diet with a mean increase of $98 \%( \pm 48)$. The ratio of C-peptide to insulin concentration during the first 120 min of the study was also found to be higher following the high-RS diet. The between-subject value for $\mathrm{SI}_{\text {oral }}$ correlated with both the insulin/C-peptide ratio $(p=0.001, r=-0.665)$ and the Cpeptide AUC $(p<0.001, r=-0.744)$.
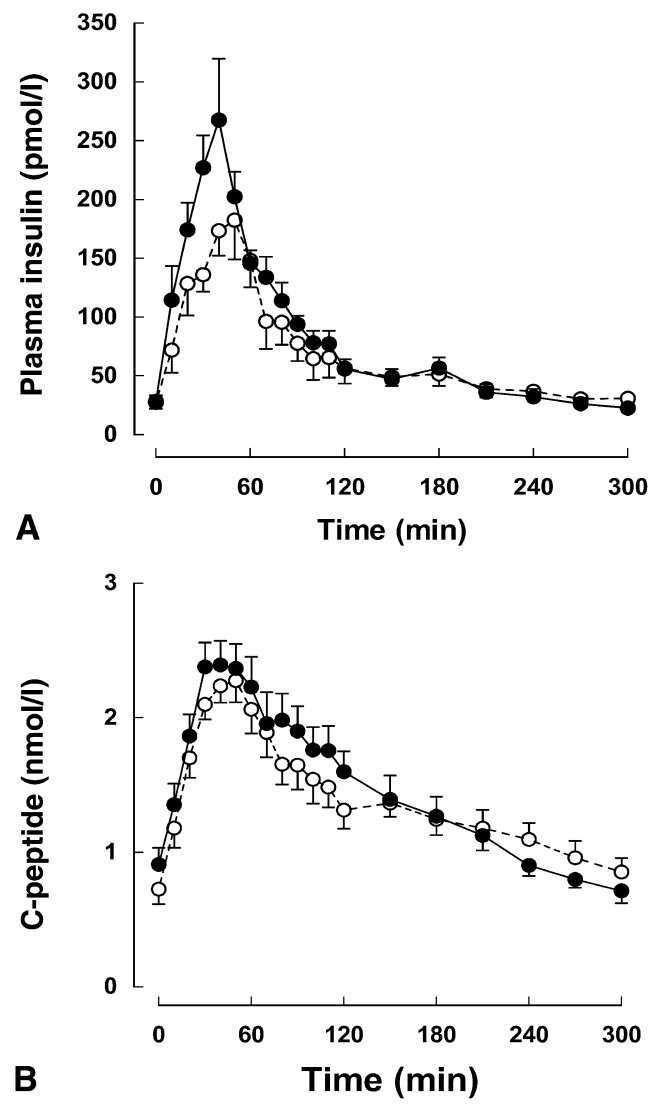

Fig. 2A, B Mean ( \pm SEM) plasma insulin and C-peptide concentrations during a meal tolerance test when preceded by either 24 h on a high-RS $(\bigcirc)$ or low-RS $(\bigcirc)$ diet. $n=10$. For insulin, repeated measures showed a significant effect of preceding diet $(p=0.038)$ and a diet vs time interaction $(p=0.014)$. For C-peptide, there was a significant time effect only $(p<0.001)$
Lipid metabolism. Following the MTT, the plasma TG concentration rose steadily to reach a peak at $240 \mathrm{~min}$ following both diets (data not shown). This could be accounted for by a rise in TG in the chylomicron-rich lipoprotein fraction and the VLDL-TG concentration. There was no difference in the plasma, chylomicron or VLDL-TG between the two diets. Differences were found in both the NEFA and 3-OHB concentrations following the two diets (Fig. 3). The fasting NEFA levels following the two diets did not differ. Following the MTT, NEFA concentrations were suppressed for the first $120 \mathrm{~min}$ before increasing to above fasting levels.
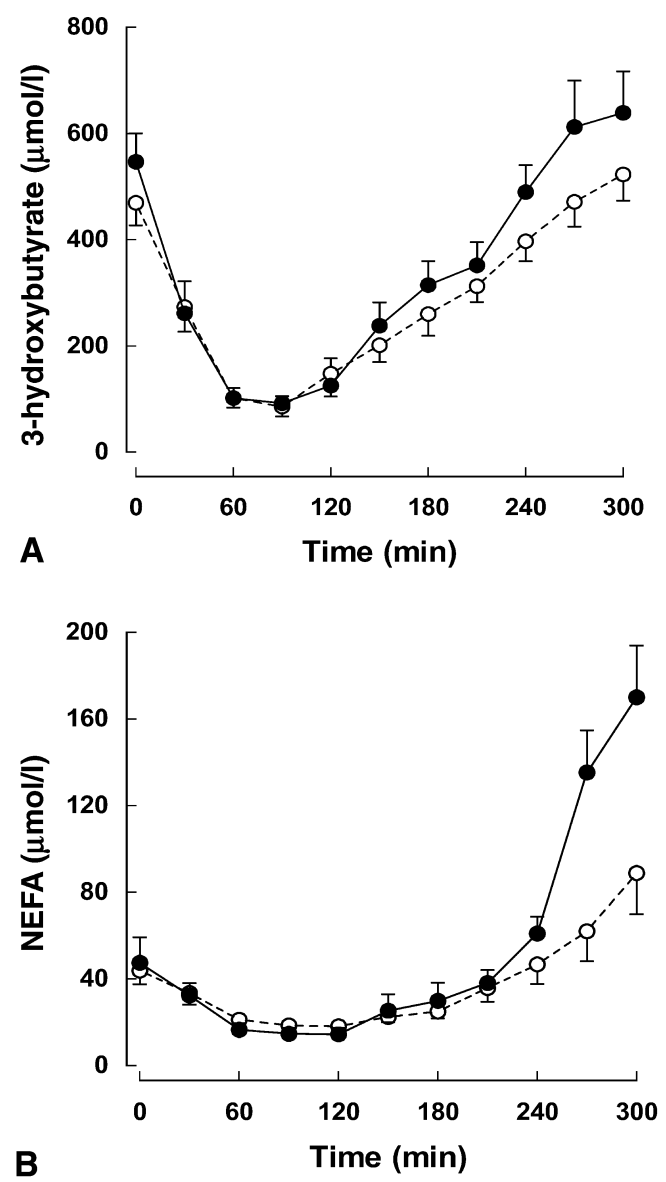

Fig. 3A, B Mean ( \pm SEM) plasma NEFA and 3-hydroxybutyrate (3-OHB) concentrations during a meal tolerance test when preceded by either $24 \mathrm{~h}$ on a high-RS $(\bigcirc)$ or low-RS $(\bigcirc)$ diet. $n=10$. For NEFA, repeated measures ANOVA showed a significant effect of preceding diet $(p=0.011)$ and $3-\mathrm{OHB}$ showed a significant diet vs meal interaction $(p<0.001)$

Table 3 Indices of insulin sensitivity following a 24-h low-RS and high-RS diet

\begin{tabular}{|c|c|c|c|c|c|}
\hline & \multicolumn{2}{|c|}{ Low RS } & \multicolumn{2}{|c|}{ High RS } & \multirow[t]{2}{*}{$p$ value } \\
\hline & Mean & SEM & Mean & SEM & \\
\hline beta-cell function $(\%)$ & 55.6 & 10.85 & 60.3 & 12.81 & ns \\
\hline SI $_{\mathrm{ORAI}}\left(\times 10^{-4} \mathrm{dl} \mathrm{kg}^{-1} \mathrm{~min}^{-1}\right.$ per $\left.\mu \mathrm{Uml}^{-1}\right)$ & 26 & 3.5 & 44 & 7.5 & 0.028 \\
\hline IAUC C-peptide/ IAUC Insulin & 9.7 & 0.69 & 18.7 & 6.5 & 0.017 \\
\hline
\end{tabular}


Table 4 Fasting $(\mu \mathrm{mol} / \mathrm{l})$ and postprandial ( $\mu \mathrm{mol} / 1.300 \mathrm{~min})$ plasma short chain fatty acid concentrations following $24 \mathrm{~h}$ on a lowand high-RS diet

\begin{tabular}{|c|c|c|c|c|c|c|}
\hline & & \multicolumn{2}{|l|}{ Low RS } & \multicolumn{2}{|l|}{ High RS } & \multirow[t]{2}{*}{$p$ value } \\
\hline & & Mean & SEM & Mean & SEM & \\
\hline Acetate & $\begin{array}{l}\text { Fasting } \\
\text { AUC }\end{array}$ & $\begin{array}{l}102.2 \\
34700\end{array}$ & $\begin{array}{c}14.89 \\
3849\end{array}$ & $\begin{array}{c}143.7 \\
41010\end{array}$ & $\begin{array}{l}35.50 \\
4062\end{array}$ & $\begin{array}{l}\mathrm{ns} \\
\mathrm{ns}\end{array}$ \\
\hline Propionate & $\begin{array}{l}\text { Fasting } \\
\text { AUC }\end{array}$ & $1452^{3.74}$ & $\begin{array}{c}1.131 \\
164.0\end{array}$ & $2052^{8.00}$ & $\begin{array}{l}1.717 \\
272.0\end{array}$ & $\begin{array}{l}0.065 \\
\mathrm{~ns}\end{array}$ \\
\hline Butyrate & $\begin{array}{l}\text { Fasting } \\
\text { AUC }\end{array}$ & $\begin{array}{c}0.78 \\
290.6\end{array}$ & $\begin{array}{l}0.381 \\
62.76\end{array}$ & $\begin{array}{l}1.31 \\
352.7\end{array}$ & $\begin{array}{l}0.308 \\
39.68\end{array}$ & $\begin{array}{l}\mathrm{ns} \\
\mathrm{ns}\end{array}$ \\
\hline
\end{tabular}

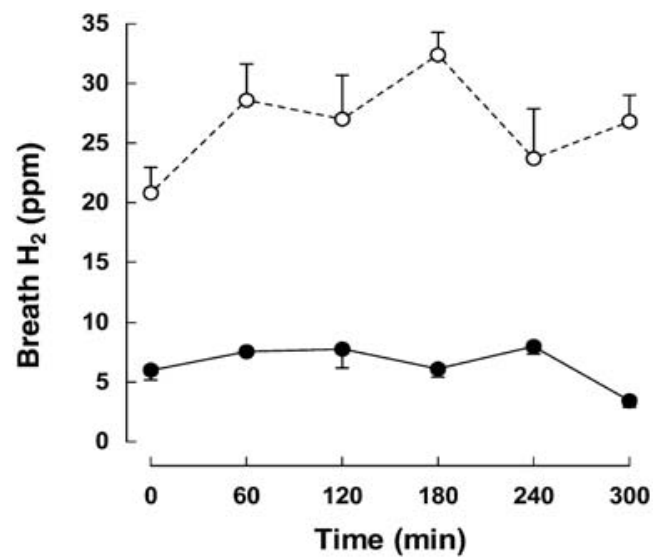

Fig. 4 Mean ( \pm SEM) breath hydrogen measurement during a meal tolerance test when preceded by either $24 \mathrm{~h}$ on a high-RS ( $\bigcirc)$ or low-RS $(\bigcirc)$ diet. $n=10$. Repeated measures ANOVA showed a significant effect of preceding diet $(p<0.001)$ and a diet vs time interaction $(p<0.001)$

By the end of the study period, NEFA levels were lower following the high-RS diet $(0.52$ vs $0.63 \mathrm{mmol} / \mathrm{l}$; $p=0.017$ ). Between subjects the postprandial AUC NEFA response correlated to both the $\mathrm{SI}_{\text {oral }}(p=0.024, r=-$ $0.503)$ and the insulin/C-peptide ratio $(p=0.043$, $r=0.456)$. The $3-\mathrm{OHB}$ concentration followed a similar pattern to that observed with NEFA except that values remain suppressed for 240 min following the MTT, before again rising in excess of fasting levels. By the end of the study period, the 3-OHB concentration was suppressed following the high-RS diet ( $88 \mathrm{vs} 170 \mu \mathrm{mol} / \mathrm{l}$; $p=0.014)$. There was a trend for this suppression in plasma 3-OHB to be correlated to the earlier lower levels of plasma insulin noted following RS ingestion although this failed to reach statistical significance $(p=0.056)$. Fasting and postprandial plasma short chain fatty acids are shown in Table 4. Concentrations did not differ following the two diets although there seemed to be a trend for higher levels following the high-RS diet.

Breath analysis. After the high-RS diet there was an increase in the fasting hydrogen levels, which was maintained throughout the study period $(p<0.001)$. The breath hydrogen level did not drop below 20 ppm following the high-RS diet (Fig. 4).

\section{Discussion}

We have shown that acute ingestion of a high-RS diet for as little as $24 \mathrm{~h}$ induced changes in tissue insulin sensitivity, hepatic insulin clearance and fatty acid metabolism. This apparent improvement in glucose tolerance during a single day has been shown previously with high-fibre foods $[25,26]$ although in these studies the effects of indigestible carbohydrates could not be differentiated from those of glycaemic index (GI). By supplementing an identical background diet we have modified RS intake without associated changes in soluble fibre, available carbohydrate or fat and so the metabolic effects observed during this study can be attributed solely to RS ingestion. These findings contrast the view that favours resistant starch ingestion has no effect on postprandial glycaemia [6], which could reflect in part the fact that the dose used in this study was higher than that normally chosen but also must take into account that our metabolic effects were noted the day following RS ingestion and not in the immediate postprandial period $[27,28]$.

The breath hydrogen levels recorded in this study during the MTT indicate that fermentation of RS was still active the day after the high-RS diet [29] whereas fermentation was minimal following the low-RS diet. Plasma SCFA were also raised although the fact that this increase did not attain statistical significance is not perhaps surprising. Studies on portal blood have shown that approximately $75 \%$ of acetate, $90 \%$ of propionate and $95 \%$ of butyrate is lost to hepaticextraction during each single-pass of blood through the liver [30] and so peripheral concentrations might not reflect portal concentrations which are likely to be high [31]. An increased portal concentration of SCFA has the potential to affect hepatocyte metabolism.

A primary observation was the reduction in plasma insulin without an accompanying change in C-peptide concentration, indicating that the differences in insulin levels noted were likely to be due to an increase in hepatic internalization of insulin rather than to differences in insulin secretion. This phenomenon has previously only been noted for viscous fibres [32]. The removal of circulating insulin is thought to be dependent 
on the binding of insulin to cell-surface receptors, before receptor-mediated endoctyosis and degradation [33]. An increase in insulin-binding to peripheral insulin receptors has been noted with high-fibre diets [34] and following rectal infusion of SCFA [35]. Any effects on hepatocyte-insulin binding are likely to be due to increased exposure of the liver to SCFA [11].

During the early phase of the MTT the main effect of prior RS ingestion was a lowering of plasma glucose concentration, despite the higher rate of insulin clearance and lower circulating insulin levels. Shortterm changes in glucose tolerance have been attributed to changes in fatty acid metabolism [36]; however, during the first $2 \mathrm{~h}$ of the MTT when insulin sensitivity was assessed there was no effect of RS on either fasting or postprandial NEFA. Lower glucose levels could also be partly attributed to a high portal concentration of propionate. Propionate has been shown to have insulin-like effects; stimulating glycolysis [14, 37], activating glycogen synthase in isolated hepatocytes [38] and reducing gluconeogenesis [37], all serving to lower circulating glucose. This tallies well with both an observed reduction in hepatic glucose production $12 \mathrm{~h}$ after insoluble fibre ingestion [25] and the high amounts of liver glycogen found in rats adapted to a high-RS diet [39]. The colon is an important site for luminal and neurally-stimulated GLP-1 release [40]. GLP-1 has been strongly implicated in postprandial oral glucose tolerance, stimulating insulin release and having independent insulinotropic effects [41]. Although GLP-1 is not thought to be directly stimulated by colonic SCFA [42], luminal bile acids and carbohydrate have been implicated [43]. In this study, prior acute dosing of RS had no effect on postprandial GLP-1 levels during the MTT. The reported effects of fermentable carbohydrate on GLP-1 levels could be due to changes in bile acid composition or the up-regulation of GLP-1 mRNA [44], an effect which we would not expect after $24 \mathrm{~h}$.

It is likely that any potential effects of SCFA [13, 37] on NEFA suppression were overwhelmed by the more potent antilipolytic effects of insulin; the depressive effect of the RS-diet on NEFA concentration was only observed late in the MTT when the effects of raised circulating insulin were removed. A reduction in NEFA following RS suggests that the earlier insulin-induced inhibition of adipose tissue lipolysis was being maintained. NEFA delivery from adipose tissue is now seen as a major determinant of both fatty acid oxidation and hepatic glucose output [45], and in the acute situation raised plasma NEFA lead to the inhibition of insulin-stimulated glucose uptake [46]. In this study, plasma NEFA suppression would seem to be a consequence of increased adipose tissue insulin sensitivity, as neither insulin levels at the end of the study period, nor levels of peripherally measured SCFA, could explain the effect. The supply of fatty acids to the liver regulates $\beta$-oxidation and hence hepatic keto- genesis; this we also found to be suppressed following RS. Plasma levels of 3-OHB and NEFA were found to correlate during the MTT, with the mean 3-OHB AUC suppressed by $10.5 \%$ and the NEFA AUC by $11.9 \%$ following RS. There was no evidence in this study of differences in fatty acid partitioning within the liver despite the documented in vitro effects of propionate on hepatic $\beta$-oxidation [47].

These results have indicated that a very high intake of RS, which could be achieved by the direct replacement of "refined-flour" with "high-RS flour" in the diet, has metabolic effects linked to the improvement in postprandial insulin sensitivity in normal healthy humans. Longer-term studies are needed to assess the dose tolerance of RS compared with other fermentable fibres and to determine the metabolic consequences of increasing RS intake in those with impaired glucose tolerance and Type 2 diabetes.

Acknowledgements. The authors would like to thank The National Starch and Chemical Company for support in providing materials and D. Araujo-Vilar from Servicio de Endocrinoloxia e Nutricion, Hospital Xeral, Spain for use of the computer program for calculation of $\mathrm{SI}_{\mathrm{ORAL}}$. This study was supported by a grant from the Biotechnology and Biological Sciences Research Council (BBSRC) UK.

\section{References}

1. Reaven GM (1995) Pathaphysiology of insulin resistance in human disease. Physiol Rev 75:473-486

2. Cameron-Smith D, Collier GR, O'Dea K (1994) Effect of soluble dietary fibre on the viscosity of the gastrointestinal contents and the acute glycaemic response in the rat. $\mathrm{Br} \mathrm{J}$ Nutr 71:563-571

3. Leclere CL, Champ M, Biollot J (1994) Role of viscous guar gums in lowering the glycaemic response after a solid meal. Am J Clin Nutr 59:914-921

4. Ludwig DS, Pereira MA, Kroenke CH (1999) Dietary fiber, weight gain, and cardiovascular disease risk factors in young adults. JAMA 282:1539-1546

5. Song YJ, Sawamura M, Ikeda K, Igawa S, Yamori Y (2000) Soluble dietary fibre improves insulin sensitivity by increasing muscle GLUT-4 content in stroke-prone spontaneously hypertensive rats. Clin Exp Pharmacol Physiol 27:41-45

6. Jenkins DJA, Kendall CWC, Axelsen M, Augustin LSA, Vuksan V (2000) Viscous and nonviscous fibres, nonabsorbable and low glycaemic index carbohydrates, blood lipids and coranary heart disease. Curr Opin Lipidol 11:49-56

7. Salmeron J, Ascherio A, Rimm EB (1997) Dietary fiber, glycaemic load, and risk of NIDDM in men. Diabetes Care 20:545-550

8. Salmeron J, Manson JE, Stampfer MJ, Colditz GA, Wing AL, Willett WC (1997) Dietary fiber, glycaemic load and risk of non-insulin dependent diabetes mellitus in women. JAMA 277:472-477

9. Jacobs DR, Meyer KA, Kushi LH, Folsom AR (1998) Whole-grain intake may reduce the risk of ischemic heart disease death in post-menopausal women: the Iowa Womens Health Study. Am J Clin Nutr 68:248-257

10. McKeown NM, Meigs JB, Liu S, Wilson PWF, Jacques PF (2002) Whole-grain intake is favourably associated with metabolic risk factors for type 2 diabetes and cardiovascu- 
lar disease in the Framingham Offspring Study. Am J Clin Nutr 76:390-398

11. Pereira MA, Jacobs DR, Pins JJ, et al. (2002) Effect of whole grains on insulin sensitivity in overweight hyperinsulinaemic adults. Am J Clin Nutr 75:848-855

12. Crouse JR, Gerson CD, DeCarli LM, Lieber CS (1968) Role of acetate in the reduction of plasma free fatty acids produced by ethanol in man. J Lipid Res 9:509-512

13. Akanji AO, Bruce MA, Frayn KN (1989) Effect of acetate infusion on energy expenditure and substrate oxidation rates in non-diabetic and diabetic subjects. Eur J Clin Nutr 43:107-115

14. Anderson JW, Bridges SR (1984) Short-chain fatty acid fermentation products of plant fiber affect glucose metabolism of isolated rat hepatocytes. Proc Soc Exp Biol Med. 177:372-376

15. Sasaki Y, Weekes TEC, Bruce JB (1977) Effects of glucose and butyrate on insulin release from perfused fragments of sheep pancreas. J Endocrinol 72:415

16. Dysseler P, Hoffem D. Estimation of resistant starch intake in Europe (1994). In: Asp NG, Van Amelsvoort JMM, Hautvast JGAJ (eds) Physiological implication of the consumption of resistant starch in man. European Commission, pp 84-85

17. Willowski I, Rechkemmer G, Pool-Zobel BL (2001) Protective role of probiotics and prebiotics in colon cancer. Am J Clin Nutr 73 (Suppl 2):451S-455S

18. MAFF (1995) Manual of Nutrition, 10th edn, vol 342 (reference book). HMSO, London

19. Elliott RM, Morgan LM, Tredger JA, Deacon S, Wright J, Marks V (1993) Glucagon-like peptide (7-36) amide and glucose dependent insulinotropic peptide secretion in response to nutrient ingestion in man: acute postprandial and 24-h secretion patterns. J Endocrinol 138:159-166

20. Karpe F, Hamsten A (1994) Determination of apolipoproteins B-48 and B-100 in triglyceride-rich lipoproteins by analytical SDS-PAGE. J Lipid Res 35:1311-1317

21. Brighenti F (1997) Simple method for quantitative analysis of short chain fatty acids in serum by gas-liquid chrmotography. In: Guillon F, Abraham G, Amado R (eds) Plant polysaccharides in human nutrition: structure, function, digestive fate and metabolic affects. INRA, Nantes, pp 114-119

22. Caumo A, Bergman RN, Cobelli C (2000) Insulin sensitivity from meal tolerance tests in normal subjects: a minimal model index. J Clin Endocrinol Metab 85:4396-4402

23. Best JD, Kahn SE, Ader M, Watanabe RM, Ni TC, Bergman RN (1996) Role of glucose effectiveness in the determinationof glucose tolerance. Diabetes Care 19:1018-1030

24. Matthews DR, Hosker JP, Rudenski AS, Naylor BA, Treacher DF, Turner RC (1985) Homeostasis model assessment: insulin resistance and $\beta$-cell function from fasting plasma glucose and insulin concentrations in man. Diabetologia 28:412-419

25. Thorburn A, Muir J, Proitto J (1993) Carbohydrate fermentation lowers hepatic glucose output in healthy subjects. Metabolism 42:780-785

26. Liljeberg HGM, Akerberg AKE, Bjorck IME (1999) Effect of the glycemic index and content of indigestible carbohydrates of cereal-based breakfast meals on glucose tolerance at lunch in healthy subjects. Am J Clin Nutr 69:647-655

27. Giacco R, Mancini M, Clemente G (1996) Metabolic effects of resistant starch in patients with NIDDM. Diabetologia 39 [Suppl]:A196

28. Jenkins DJA, Vuksan V, Kendall CWC, P. W, Jeffcoat R, Waring S (1998) Physiological effects of resistant starches as colonically available forms of lente carbohydrate. J Am Coll Nutr 17:609-616
29. Bond JH, Levitt MD (1972) Use of pulmonary hydrogen measurements to quantitate carbohydrate absorption. Study of partially gastrectomized patients. J Clin Invest 51:1219-1225

30. Peters SG, Pomare EW, Fisher CA (1992) Potal and peripheral blood short chain fatty acids concentrations after caecal lactulose instillation at surgery. Gut 33:1249-1252

31. Cummings JH (1995) Short chain fatty acids. In: Gibson GR, Macfarlane GT(eds) Human colonic bacteria: role in nutrition, physiology and pathology. CRC Press, Boca Raton, Fla., pp 101-130

32. Gatenby SJ, Ellis PR, Morgan LM, Judd PA (1996) The effects of partially depolimorised guar gum on metabolic variables in NIDDM patients. Diabet Med 13:358-354

33. Sonne O (1988) Receptor-mediated endocytosis and degradation of insulin. Physiol Rev 68:1129-1196

34. Hjollund E, Pedersen O, Richelsen B, Beck-Nielsen H, Sorensen NS (1983) Increased insulin binding to adipocytes and monocytes and increased insulin sensitivity of glucose transport and metabolism in adipocytes from non-insulin dependent diabetics after a low-fat/high-starch/high-finer diet. Metabolism 32:1067-1075

35. Alamowitch C, Boillot J, Boussairi A, et al. (1996) Lack of effect of an acute ileal perfusion of short chain fatty acids on glucose metabolism in healthy men. Am J Physiol Endocrinol Metab 271:E199-E204

36. Wolever T, Bentum-Williams A, Jenkins DJA (1995) Physiological modulation of plasma free fatty acid concnetration by diet: implications in non-diabetic subjects. Diabet Care 18:962-970

37. Venter CS, Vorster HH, Cummings JH (1990) Effects of dietary propionate on carbohydrate and lipid metabolism in healthy volunteers. Am J Gastroenterol 85:549-553

38. Morand C, Remesey C, Levrat M-A, Demigne C (1992) Replacement of digestible wheat starch by resistant cornstarch alters splanchnic metabolism in rats. J Nutr 122:345-354

39. Christ B, Jungermann K (1987) Sub-compartmentation of the cytosolic glucose-6-phosphate pool in cultures rat hepatocytes. FEBS Lett 221:375-380

40. Robertson MD, Livesey G, Morgan LM, Hampton SM, Mathers JC (1999) The influence of the colon on postprandial glucagon-like peptide 1 (7-36) amide concentration in man. J Endocrinol 161:25-31

41. Drucker DJ (2002) Biological actions and therapeutical potential of the glucagon-like peptides. Gastroenterology 122:531-544

42. Cuche G, Cuber JC, Malbert CH (2000) Ileal short chain fatty acids inhibit gastric motility by a humoral pathway. Am J Physiol Gastrointest Liver Physiol 279:G925-G930

43. Dumoulin V, Moro F, Barcelo A, Dakka T, Cuber JC (1998) Peptide YY, glucagon-like peptide 1, and neurotensin responses to luminal factors in the isolated vascularly perfused rat ileum. Endocrinology 139:3780-3785

44. Reimer RA, McBurney MI (1996) Dietary fiber modulates intestinal proglucagon messenger ribonucleic acid and postprandial secretion of glucagon-like peptide- 1 and insulin in rats. Endocrinology 137:3948-3956

45. Bergman RN (2000) Non-esterified fatty acids and the liver: why is insulin secreted into the portal vein? Diabetologia 43:946-952

46. Boden G, Lebed B, Schatz M, Homko C, Lemieux S (2001) Effects of acute changes of plasma free fatty acids on intramyocellula fat content and insulin resistance in healthy subjects. Diabetes 50:1612-1617

47. Brass EP, Fennessey PV, Miller LV (1986) Inhibition of oxidative metabolism by propionic acid and its reversal by carnitine in isolated rat hepatocytes. Biochem J 236: $131-136$ 